\title{
Sustained release procainamide in patients with myocardial infarction
}

\author{
John Birkhead, ${ }^{1}$ Tom Evans, Patricia Mumford, Eulogio Martinez, and David Jewitt ${ }^{2}$ \\ From MRC Cardiovascular Unit, Division of Cardiovascular Medicine, Department of Medicine, \\ Royal Postgraduate Medical School, London
}

\begin{abstract}
Sustained release procainamide tablets were administered to 34 patients 48 hours after the onset of an acute myocardial infarct. Therapeutic blood levels of procainamide in the range of 4 to $8 \mu \mathrm{g} / \mathrm{ml}$ were consistently achieved using an 8-hourly maintenance dose of $1.5 \mathrm{~g}$ after an initial loading dose of $2 \mathrm{~g}$. In contrast conventional procainamide capsules administered to 21 comparable patients repeatedly failed to produce plasma concentrations in the therapeutic range, despite the administration of a maintenance dose of $375 \mathrm{mg} 3$ hourly, after a loading dose of $1 \mathrm{~g}$. It is suggested that when the oral administration of procainamide is indicated for the management of ventricular arrhythmias after myocardial infarction, a sustained release preparation should be used.
\end{abstract}

In the acute phase after myocardial infarction, ventricular arrhythmias are a common cause of death. They also occur in the weeks and months after infarction (Norris et al., 1968; Lawrie, 1969; Sloman et al., 1970). The management of such patients is initially with intravenous lignocaine, but subsequent management over a period of days or weeks requires an oral antiarrhythmic drug. Procainamide is a potent antiarrhythmic agent which is active against both ventricular and supraventricular arrhythmias. Oral procainamide has been reported to provide effective prophylaxis against ventricular arrhythmias during the acute phase of infarction (Koch-Weser et al., 1969). The absorption of procainamide is normally complete within two hours and elimination is predominantly by renal glomerular filtration and tubular excretion (Koch-Weser, 1971) though a small amount is metabolized to $\mathrm{N}$-acetyl procainamide (Dreyfuss et al., 1972). Elimination is rapid and the biological half-life averages 3.5 hours. The therapeutic range is between 4 and $8 \mu \mathrm{g} / \mathrm{ml}$ (KochWeser and Klein, 1971), though other workers (Giardina, Heissenbuttel, and Bigger, 1973) have suggested that $10 \mu \mathrm{g} / \mathrm{ml}$ can be approached without toxicity. In order to maintain plasma procainamide

1Present address: Radcliffe Infirmary, Oxford.

'Present address and address for correspondence: King's College Hospital, Denmark Hill, London, SE5.

Received 18 August 1975. levels within this therapeutic range, the importance of a 3-hourly dosage regimen has been stressed (Koch-Weser et al., 1969). Recently Shaw and coworkers (1974) have evaluated a 4-hourly dosage regimen using 375 to $500 \mathrm{mg}$ and noted that it was unsatisfactory in maintaining effective plasma levels in 36 per cent of patients even at the highest dose. The inconvenience of administering procainamide on a 3- or 4-hourly basis even in hospital is readily apparent. It is magnified when the drug is prescribed on an outpatient basis. A sustained release preparation of procainamide would have major advantages.

The object of the present study was to estimate the plasma levels obtained using a sustained release preparation of procainamide in patients with acute myocardial infarction. Furthermore, a comparison was made between these results and those obtained in a similar group of patients with conventional procainamide tablets.

\section{Patients and Methods}

Patients who were admitted to the coronary care unit of Hammersmith Hospital and in whom a diagnosis of myocardial infarction was made on W.H.O. criteria were eligible for the study. Patients with severe heart failure, second-degree, or complete heart block, or pre-existing renal disease were excluded. Patients who fulfilled these criteria and who had required a lignocaine infusion to control ventricular tachyarrhythmias in 
the initial 48 hours after admission, were then treated with either conventional procainamide tablets ${ }^{1}$ or sustained release procainamide ${ }^{2}$.

Conventional procainamide tablets were administered as follows:

1) 9 patients received a loading dose of $1 \mathrm{~g}$ procainamide.

2) 13 patients received $375 \mathrm{mg}$ procainamide 3-hourly.

Sustained release procainamide was administered as follows:

1) 6 patients received a single loading dose of $1.5 \mathrm{~g}$ procainamide.

2) 15 patients received a loading dose of $2 \mathrm{~g}$ procainamide.

3) 8 patients received a loading dose of $2 \mathrm{~g}$ procainamide followed by $1.5 \mathrm{~g} 8$-hourly as a maintenance dose.

4) 5 patients received a loading dose of $2 \mathrm{~g}$ procainamide followed by $1.5 \mathrm{~g}$ at 4 hours and then $1.5 \mathrm{~g} 8$-hourly as a maintenance dose.

In the early phase of complicated myocardial infarction, blood urea may rise and the creatinine clearance may fall (Hutton et al., 1970). Since procainamide is primarily excreted in the urine unchanged and its clearance correlates with creatinine clearance, the studies reported here have been limited to patients in whom the blood urea at the time of study was normal.

The nature of the study was explained to all patients and their consent obtained.

\section{Blood samples}

When loading doses of conventional procainamide were being administered the initial samples were taken at half-hourly intervals in order to identify early peaks; subsequently, hourly samples were taken for a total of at least 6 hours. With maintenance therapy on standard tablets, samples were taken at hourly intervals for 6 hours when $375 \mathrm{mg}$ procainamide was administered 3hourly. These samples were taken at least 48 hours after the initiation of maintenance therapy when stable blood levels should have been achieved. With the sustained release procainamide preparation, the effects of single loading doses were followed at hourly intervals for at least 8 hours. With maintenance therapy after an initial dose, samples were obtained at 4-hourly intervals for at least $\mathbf{4 8}$ hours, omitting one sample in the early morning when the patients were asleep.

\section{Plasma procainamide estimation}

$5 \mathrm{ml}$ venous blood was withdrawn into lithium heparin tubes and centrifuged within 4 hours. The plasma was then removed and stored at $4^{\circ} \mathrm{C}$ until analysis within the next 5 days. Procainamide is not readily decomposed by plasma enzymes (Moe and Abildskov, 1970). The plasma concentration was measured spectrofluorometrically as described by Koch-Weser et al. (1969). The percentage recovery was calculated for each patient by the inclusion of a known standard concentration of procainamide. The reliability of the method was tested by analysis of samples from a plasma pool

${ }^{1}$ Pronestyl (Squibb).

2Procaine Amide Durules (AB Hassle). with a known procainamide content. This gave an average recovery of $95 \pm 1 \cdot 7$ per cent.

\section{Results}

\section{A) Conventional procainamide tablets}

With the initiation of therapy it is important to reach therapeutic plasma levels early. KochWeser has stressed the value of using a loading dose and suggested that twice the oral maintenance dose is appropriate (Koch-Weser et al., 1969). In the present study a $1 \mathrm{~g}$ loading dose was not adequate and only just attained therapeutic levels (see Fig. 1). The time taken to achieve this level is $117 \pm 27$ minutes.

The plasma levels achieved after receiving 375 $\mathrm{mg}$ of procainamide for $\mathbf{4 8}$ hours administered as a tablet 3-hourly in 13 patients are shown in Fig. 2. It is apparent that in this study $375 \mathrm{mg}$ conventional procainamide given 3-hourly did not maintain adequate therapeutic plasma levels during the period of observation.

\section{B) Sustained release procainamide}

Six patients were given a $1.5 \mathrm{~g}$ loading dose of sustained release procainamide. A $2 \mathrm{~g}$ loading dose was given to a further 15 patients. Therapeutic levels were reached within two hours of initiation of the therapy (Fig. 3). The peak level after $2 \mathrm{~g}$ sustained release procainamide was $7 \cdot 4 \pm 0.4$ $\mu \mathrm{g} / \mathrm{ml}$ at $160 \pm 16$ minutes, and this compared with $6.0 \pm 0.9 \mu \mathrm{g} / \mathrm{ml}$ at $117 \pm 27$ minutes after $1 \mathrm{~g}$ conventional procainamide tablets. A single initial

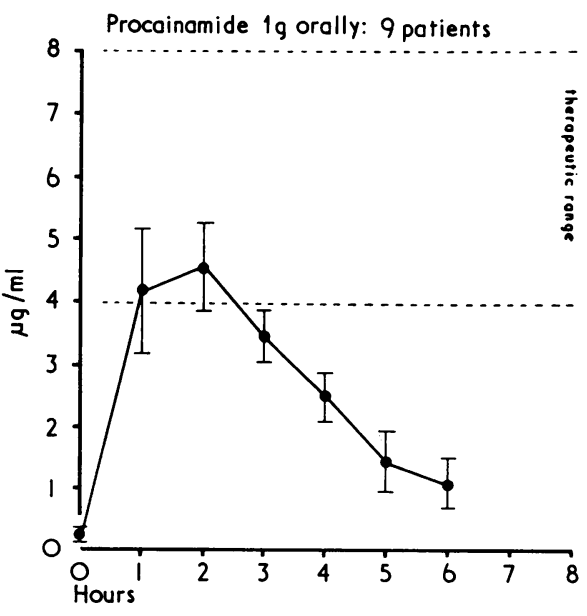

FIG. 1 Plasma levels of procainamide after $1 \mathrm{~g}$ loading dose of conventional tablets. 


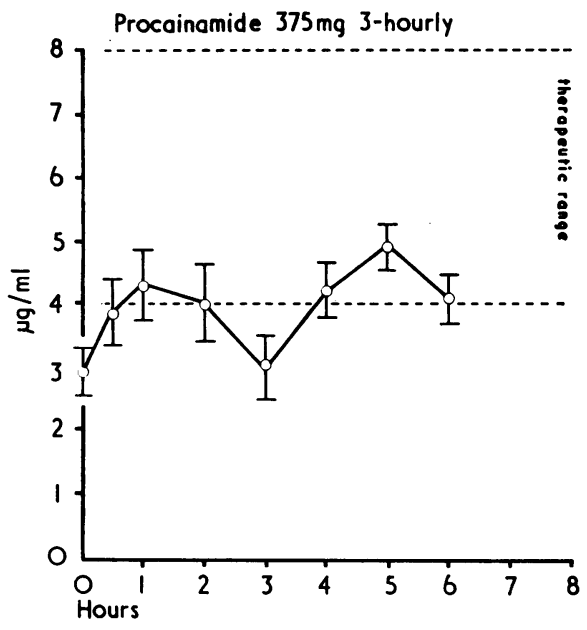

FIG. 2 Plasma levels of procainamide in 13 patients who received $375 \mathrm{mg}$ of conventional tablets 3-hourly for at least 48 hours.

dose of $2 \mathrm{~g}$ sustained release procainamide maintains the plasma level in the therapeutic range for 5 to 6 hours in the first 8-hour period without entering the toxic range. When $1.5 \mathrm{~g}$ of the sustained release preparation was given, the peak plasma level of $7 \cdot 1 \pm 1.0 \mu \mathrm{g} / \mathrm{ml}$ was achieved in $210 \pm 46$ minutes.

When a maintenance dose of $1.5 \mathrm{~g}$ was administered 8-hourly after a $2 \mathrm{~g}$ loading dose adequate plasma levels were achieved continuously up to 48 hours with the exception of a short period before

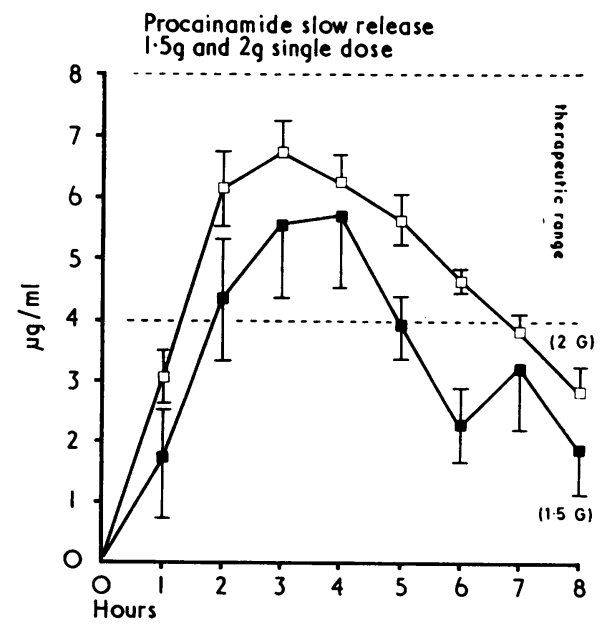

FIG. 3 Plasma levels of procainamide after administration of $1.5 \mathrm{~g}$ (6 patients) and $2 \mathrm{~g}$ (15 patients) of sustained release preparation. the first maintenance $1.5 \mathrm{~g}$ dose as shown in Fig. 4.

In an attempt to avoid the short period outside the therapeutic range after the $2 \mathrm{~g}$ loading dose and before starting maintenance therapy, 5 patients were studied in whom $1.5 \mathrm{~g}$ were given 4 hours after the initial $2 \mathrm{~g}$ loading dose and then an 8hourly maintenance dose of $1.5 \mathrm{~g}$ started. This, however, had the effect of raising the plasma levels towards the toxic range.

\section{Side effects}

There were no major side effects with conventional or sustained release procainamide in the shortterm studies performed here.

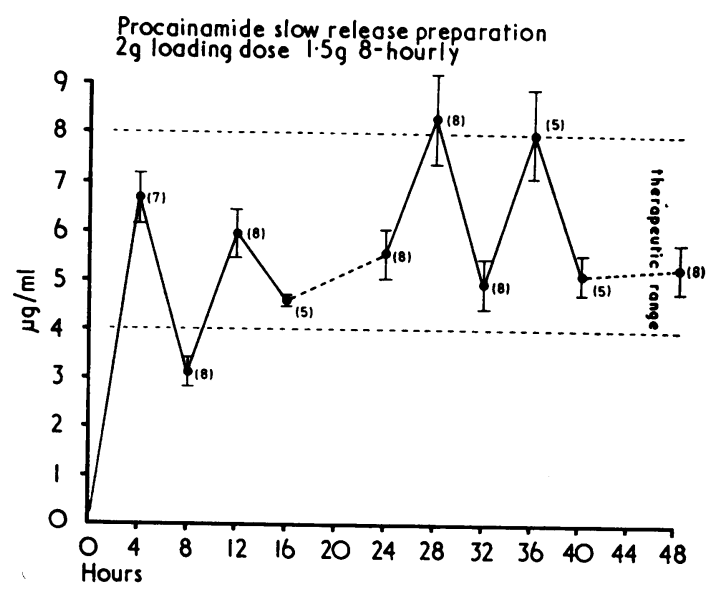

FIG. 4 Plasma levels of procainamide in 8 patients who received $1.5 \mathrm{~g}$ sustained release preparation 8 hourly after $2 \mathrm{~g}$ loading dose.

\section{Discussion}

The original work of Koch-Weser related the plasma levels of procainamide to its therapeutic and toxic side effects and formulated a 3-hourly regimen in order to achieve stable and effective plasma levels (Koch-Weser et al., 1969; KochWeser, 1971; Koch-Weser and Klein, 1971). In the present study the practical value of this regimen was not confirmed since in patients weighing 54.4 to $90.7 \mathrm{~kg}$, conventional procainamide capsules in a dose of $375 \mathrm{mg}$ given 3-hourly failed to maintain adequate plasma levels. Shaw and co-workers found that $500 \mathrm{mg}$ conventional procainamide given 4-hourly was also unsatisfactory in $36 \mathrm{per}$ cent of patients (Shaw et al., 1974). It is not easy to justify the use of a prophylactic drug on a 3hourly basis for anything but a limited period. 
For these reasons we concluded that in terms of the plasma level achieved conventional procainamide therapy is impracticable and unsatisfactory in the management of patients with ventricular arrhythmias after myocardial infarction.

The formulation of procainamide as a sustained release preparation removes the sharp peaks in blood plasma level that may be observed one or two hours after conventional procainamide and which are potentially toxic. The dissolution of sustained release procainamide persists over 6 hours in vitro compared with 5 minutes with the conventional tablets (C. Graffner, G. Johnsson, and J. Sjogren, 1973, personal communication). It is apparent that $2 \mathrm{~g}$ of the sustained release preparation followed by $1.5 \mathrm{~g}$ given 8 -hourly orally will provide plasma levels within the therapeutic range from 2 hours onwards. There is a brief fall below the therapeutic range just before administration of the first maintenance dose. In an effort to avoid this the first maintenance dose of $1.5 \mathrm{~g}$ was administered at 4 hours instead of 8 hours but this produced potentially toxic plasma levels, though side effects themselves were not recorded.

The sustained release preparation has not been used during the first 48 hours after infarction. During this time absorption and excretion of the drug may be influenced by minor and transient degrees of heart failure. It may be predicted that as with the conventional preparation some reduction in dose would be appropriate for patients with heart failure or raised blood urea. Measurement of plasma levels is necessary in these patients in order to achieve the appropriate dosage.

The period of administration of the sustained release preparation was 48 hours. During this period no side effects were noted. It is possible that either the serological or clinical manifestations of the systemic lupus erythematosus syndrome, which are known to be potential complications of conventional procainamide therapy (Fakhro, Ritchie and Lown, 1967; Molina et al., 1969; Kosowsky et al., 1973) may develop with prolonged use of the sustained release preparation. The changes are reversed by discontinuing therapy but serological testing and clinical observation to detect the appearance of this syndrome would be mandatory if prolonged therapy was thought to be justified.

The present study indicates that when sustained release procainamide is administered to patients 48 hours after the onset of myocardial infarction stable and therapeutic blood levels can be consistently achieved using 8-hourly administration. It is suggested that such a sustained release prepara- tion should be used whenever the drug is indicated for oral therapy in patients after myocardial infarction. A controlled study of its therapeutic value in the prevention of recurrent ventricular arrhythmias and particularly recurrent ventricular fibrillation during the first three months after myocardial infarction would be justified.

\section{References}

Dreyfuss, J., Bigger, J. T., Cohen, A. I., and Schreiber, E. C. (1972). Metabolism of procainamide in the rhesus monkey and man. Clinical Pharmacology and Therapeutics, 13, 366.

Fakhro, A. M., Ritchie, R. F., and Lown, B. (1967). Lupuslike syndrome induced by procainamide. American fournal of Cardiology, 20, 367.

Giardina, E. G. V., Heissenbuttel, R. H., and Bigger, J. T. (1973). Intermittent intravenous procaine amide to treat ventricular arrhythmias. Annals of Internal Medicine, $78,183$.

Hutton, I., Pack, A. I., Lindsay, R. M., and Laurie, T. D. V. (1970). Clinical significance of renal haemodynamics in acute myocardial infarction. Lancet, 2, 123.

Koch-Weser, J. (1971). Pharmacokinetic of procainamide in man. Annals of the New York Academy of Sciences, 179, 370.

Koch-Weser, J., and Klein, S. W. (1971). Procainamide dosage schedules, plasma concentrations, and clinical effects. Fournal of the American Medical Association, 215, 1454.

Koch-Weser, J., Klein, S. W., Foo-Canto, L. L., Kestor, J. A., and De Sanctis, R. W. (1969). Antiarrhythmic prophylaxis with procainamide in acute myocardial infarction. New England fournal of Medicine, 281, 1253.

Kosowsky, B. D., Taylor, J., Lown, B., and Ritchie, R. F. (1973). Long-term use of procaine amide following acute myocardial infarction. Circulation, 47, 1204.

Lawrie, D. M. (1969). Long-term survival after ventricular fibrillation complicating acute myocardial infarction. Lancet, 2, 1085.

Moe, G. K., and Abildskov, J. A. (1970). Antiarrhythmic drugs. In The Pharmacological Basis of Therapeutics, 4th ed., p. 720. Macmillan, London.

Molina, J., Dubois, E. L., Bilitch, M., Bland, S. L., and Friou, G. J. (1969). Procainamide-induced serologic changes in asymptomatic patients. Arthritis and Rheumatism, 12, 608.

Norris, R. M., Bensley, K. E., Caughey, D. E., and Scott, P. J. (1968). Hospital mortality in acute myocardial infarction. British Medical fournal, 3, 143.

Shaw, T. R. D., Kumana, C. R., Royds, R. B., Padgham, C. M., and Hamer, J. (1974). Use of plasma levels in evaluation of procainamide dosage. British Heart fournal, 36, 265.

Sloman, G., Dowling, J., Thompson, P., Hunt, D., Brown, R., and Ferguson, J. (1970). Prevalence of malignant arrhythmias in acute myocardial infarction. In Symposium on Cardiac Arrhythmias, p. 677. Ed. by E. Sandoe, E. Flensted-Jensen, and K. H. Olsen. Astra, Södertälje, Sweden.

Requests for reprints to Dr. David Jewitt, King's College Hospital, Denmark Hill, London SE5 9RS. 